\title{
Association Between Weight Change, Clinical Outcomes, and Health Care Costs in Patients with Type 2 Diabetes
}

\author{
Jayanti Mukherjee, PhD; Catarina Sternhufvud, MSc; Nancy Smith, MS; Kelly Bell, PharmD, MSPhr; \\ Marni Stott-Miller, PhD; Donna McMorrow, BS; and Stephen Johnston, MA
}

\begin{abstract}
BACKGROUND: Previous research suggests that weight loss is associated with decreases in health care costs among individuals with type 2 diabetes mellitus (T2DM) and that weight change can affect clinical measures, including hemoglobin A1c (A1c), low-density lipoprotein cholesterol (LDLC), and blood pressure. Previous research has also demonstrated more pronounced impact of weight change among patients with T2DM who are obese and have no evidence of cardiovascular disease (CVD).
\end{abstract}

OBJECTIVES: To (a) examine the association between weight change and all-cause and diabetes-related health care costs among patients with T2DM; (b) examine the association between weight change and select clinical measures among patients with T2DM; and (c) analyze a subgroup of obese patients with no previous CVD.

METHODS: This retrospective, observational cohort study used U.S. insurance claims linked to laboratory and electronic medical records. This study included patients with T2DM aged 18 years or older who added or switched to a nonmetformin antidiabetes medication after metformin monotherapy between January 1, 2007, and June 30, 2012 (date of add/switch was the index date). The primary predictor was percentage weight change (PWC) between a weight measurement at index and a follow-up measurement 6 months later; PWC ranged from negative (weight loss) to positive (weight gain). Outcomes, measured in the 12-month period beginning at the time of follow-up weight measurement, included all-cause and diabetes-related health care costs and achievement of thresholds for A1c, blood pressure, and LDL-C. Multivariable models quantified the association between PWC (linear effect) and study outcomes.

RESULTS: A total of 1,520 patients (mean age 55 years; $47 \%$ female) were included, with 780 patients (mean age 53 years; $51 \%$ female) in the subgroup sample. Mean (SD) index weight and PWC were 224.6 (52.8) lbs and $+0.2 \%(4.7 \%)$ in the primary analysis, and $241.3(47.3)$ lbs and $-0.2 \%$ $(4.6 \%)$ in the subgroup sample. In adjusted analyses, decreasing PWC was associated with decreasing diabetes-specific pharmacy costs $(P<0.001)$ in the primary analysis sample and with decreasing all-cause pharmacy costs $(P=0.018)$, diabetes-specific total costs $(P=0.039)$, diabetes-specific medical costs $(P=0.002)$, and diabetes-specific pharmacy costs $(P<0.001)$ in the subgroup sample. PWC was not associated with all-cause total health care costs or all-cause medical costs in either sample. In adjusted analyses, decreasing PWC was also associated with increasing odds of attaining the A1c goals of $<6.5 \%(P<0.001)$ and $<7.0 \%(P<0.001)$ in the primary analysis sample and increasing odds of attaining the A1c goals of $<6.5 \%$ $(P<0.001),<7.0 \%(P<0.001)$, and $<8.0 \%(P=0.010)$ in the subgroup sample. PWC was not associated with any of the other clinical measures in either of the study samples.

CONCLUSIONS: This real-world study suggests that among patients with T2DM, weight loss over a short-term (6-month) period is associated with positive impact on attainment of A1c goals and decreased diabetes-specific pharmacy costs over the subsequent 12 months. In the subset of patients who were obese and had no previus CVD, weight loss over the 6-month period was also associated with decreased all-cause pharmacy costs, diabetes-specific medical costs, and diabetes-specific total health care costs. Future research is warranted to examine whether these associations change over longer-term periods of follow-up.

J Manag Care Spec Pharm. 2016;22(5):449-66

Copyright $\odot 2016$, Academy of Managed Care Pharmacy. All rights reserved.

\section{What is already known about this subject}

Weight loss has been shown to improve glycemic control and cardiometabolic risk factors among individuals with type 2 diabetes mellitus (T2DM).

Previous studies suggest that weight loss among individuals with T2DM may reduce health care costs.

Ten-year follow-up of patients in the Look AHEAD (Action For Health in Diabetes) study demonstrated that such associations were most strongly observed among obese patients with T2DM and no cardiovascular disease (CVD).

\section{What this study adds}

This study is the first to characterize the economic and clinical impact of weight change among patients with T2DM who specifically added to or switched treatment from metformin, representing a clinical juncture at which a wide variety of potential antidiabetes medications with varying weight change properties are available for second-line treatment

Subgroup analysis undertaken among obese patients with T2DM and no previous CVD showed a particularly pronounced effect of weight loss on economic outcomes; such patients represent a clinically meaningful subgroup, given that over $50 \%$ of patients with T2DM are obese and over $80 \%$ of patients with T2DM are free of CVD early ( 0 -10 years) in the course of their disease. Weight loss increased the likelihood of attainment of common goals for glycemic control among patients with T2DM, underscoring the importance of weight management to the primary goal of glycemic control in the management of diabetes.

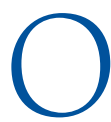
bservational studies of patients with type 2 diabetes mellitus (T2DM) have associated obesity and increased weight with a variety of undesirable circumstances, such as reduced glycemic control, ${ }^{1-4}$ increased risk of cardiovascular disease (CVD), ${ }^{5,6}$ and increased risk of therapy discontinuation, ${ }^{7}$ which may consequently add to the clinical and economic burden of T2DM. Indeed, previous studies examining the 
economic impact of changes in weight among patients with T2DM, or specific subsets thereof, have generally found that weight gain (loss) is associated with increases (decreases) in allcause and/or diabetes-specific health care utilization and costs. ${ }^{7-10}$

The American Diabetes Association (ADA) and European Association for the Study of Diabetes (EASD) recommend weight loss for overweight (body mass index $[\mathrm{BMI}] \geq 25 \mathrm{~kg} / \mathrm{m}^{2}$ ) and obese $\left(\mathrm{BMI} \geq 30 \mathrm{~kg} / \mathrm{m}^{2}\right)$ individuals with diabetes and specifically note that among these patients relatively small changes in body weight that are achieved through intensive lifestyle intervention can improve fitness, glycemic control, and cardiovascular risk factors. ${ }^{11,12}$ These recommendations are largely based on data collected as part of the Look AHEAD (Action For Health in Diabetes) study, which randomly assigned individuals with T2DM who were at least overweight to an intensive lifestyle intervention (ILI) or a diabetes support and education comparator. ${ }^{13}$ In that study, weight loss of $5 \%$ to $<10 \%$ achieved through ILI over a 1-year period was associated with statistically significant improvements in CVD risk factors. ${ }^{14}$ Although this reduction in risk was not maintained in follow-up of 9.6 years, ${ }^{15}$ analyses of participants' 10-year health care cost data demonstrated that ILI reduced health care utilization and costs among patients with no history of CVD. ${ }^{16}$ The authors concluded that such interventions may be most beneficial to overweight/obese individuals with T2DM before CVD is diagnosed.

The primary objective of this study was to examine the association between weight change and all-cause and diabetes-related health care costs. A secondary objective was to examine the association between weight change and clinical outcomes as defined in the 2014 National Committee for Quality Assurance (NCQA)/Healthcare Effectiveness Data and Information Set (HEDIS) Comprehensive Diabetes Care measures among patients with T2DM. We sought to characterize the economic impact of weight change among patients who added to or switched treatment from metformin, representing a population for which metformin monotherapy may have failed. Furthermore, this point in patient treatment was chosen because, whereas metformin monotherapy is clearly delineated in the ADA and EASD guidelines as first-line therapy for patients with type 2 diabetes, a wide variety of potential antidiabetes medications with varying weight change properties are available for second-line treatment. ${ }^{12}$

Subanalyses were also undertaken among obese patients with T2DM and no previous CVD, a clinically meaningful subgroup, given that over $50 \%$ of patients with T2DM are obese and over $80 \%$ of patients with T2DM are free of CVD early $(0-10$ years $)$ in the course of their disease. ${ }^{17-20}$

\section{Methods}

\section{Data Source}

This study used administrative claims, electronic medical records (EMRs), and laboratory results contained in the Truven Health MarketScan Claims-EMR Linked Database and the MarketScan Lab Database. The MarketScan Claims-EMR Linked Database comprises EMRs from a nationwide network of more than 30,000 health care providers using a common EMR system. These EMRs are linked, at a patient level, to enrollment information; demographic information; and inpatient medical, outpatient medical, and outpatient pharmacy claims data collected from over 300 large, self-insured U.S. employers and over 25 U.S. health plans. The database includes information for individuals who are either under the age of 65 and are the primary insured or a spouse or dependent thereof, or who are Medicare-eligible (primarily representing individuals aged 65 years or older) and have supplemental insurance paid for by their current or former employers. Laboratory results from the MarketScan Lab Database were also linked, at a patient level, to the Claims-EMR Linked Database when possible. All study data in the MarketScan databases are deidentified and fully compliant with the Health Insurance Portability and Accountability Act (HIPAA) of 1996.

All study variables were measured from the databases using International Classification of Diseases, Ninth Revision, Clinical Modification (ICD-9-CM) diagnosis and procedure codes, Current Procedural Terminology (CPT) codes, Healthcare Common Procedure Coding System (HCPCS) codes, National Drug Code (NDC) numbers, EMR observation key identifiers, and Logical Observation Identifiers Names and Codes (LOINC), as appropriate. Generic names of all study medications and all ICD-9-CM, CPT, HCPCS, EMR identifiers, and LOINC codes used in this study are available in Appendix A (available in online article). Unless otherwise noted, diagnoses and procedures were searched for in all diagnosis/procedure positions on the administrative claims.

\section{Study Sample Selection Criteria and Time Periods}

Figure 1 displays a flowchart of the sample selection process. The study sample comprised patients with $\geq 1$ outpatient pharmacy claim for metformin that was followed by $\geq 1$ outpatient pharmacy claim for a nonmetformin antidiabetes medication between January 1, 2007, and June 30, 2012. The date of the claim for the nonmetformin antidiabetes medication was designated as the index date. Patients were required to be aged 18 years or older on the index date and have continuous enrollment in medical and pharmacy benefits for 6 months before the index date (baseline period) and for $\geq 18$ months after the index date (follow-up period). Patients were required to have $\geq 1$ outpatient pharmacy claim for metformin, but no outpatient pharmacy claims for any other antidiabetes medication during the baseline period. Patients additionally were required to have $\geq 1$ medical claim with a diagnosis of T2DM during the baseline period or on the index date. Patients were excluded if they had $\geq 1$ medical claim with a diagnosis or procedure (where applicable) of type 1 diabetes, gestational diabetes, pregnancy, or bariatric surgery during the baseline or follow-up periods. 


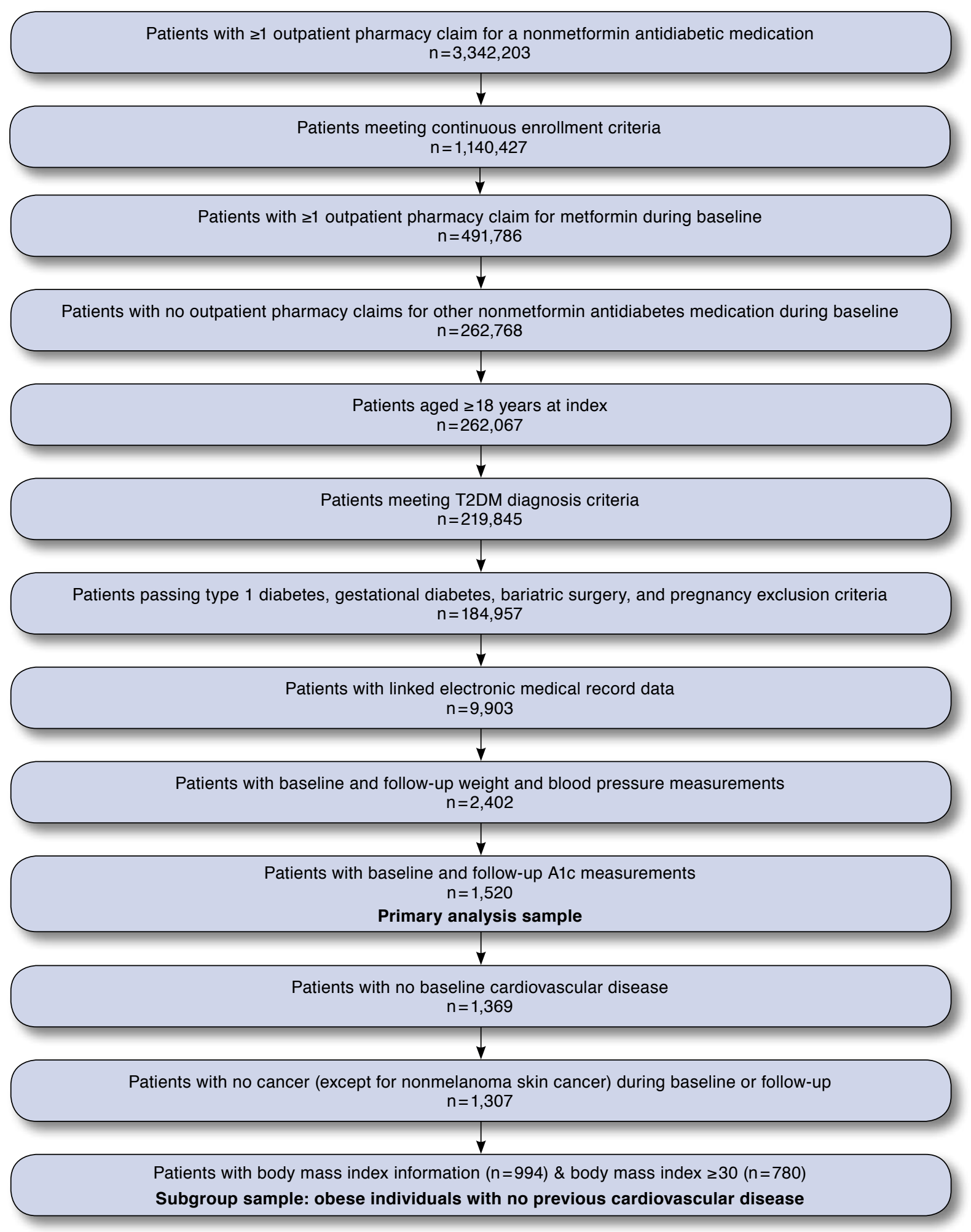

Alc =hemoglobin A1c; T2DM = type 2 diabetes mellitus. 


\begin{tabular}{|c|c|c|c|c|c|c|c|c|c|}
\hline \multirow[b]{3}{*}{ Age, mean [SD] } & \multicolumn{5}{|c|}{ Primary Analysis Sample } & \multicolumn{4}{|c|}{ Subgroup Sample ${ }^{a}$} \\
\hline & \multicolumn{2}{|c|}{$\begin{array}{c}\text { Weight Gain } \\
\text { Group } \\
\mathbf{n}=325\end{array}$} & \multicolumn{2}{|c|}{$\begin{array}{c}\text { Nonweight Gain } \\
\text { Group }^{\mathbf{b}} \\
\mathbf{n}=1,195\end{array}$} & \multirow{2}{*}{$\begin{array}{c}P \text { Value } \\
0.741\end{array}$} & \multicolumn{2}{|c|}{$\begin{array}{c}\text { Weight Gain } \\
\text { Group } \\
\mathbf{n}=134\end{array}$} & $\begin{array}{l}\text { Nonweight Gain } \\
\text { Group } \\
\mathbf{n}=646\end{array}$ & \multirow{2}{*}{$\begin{array}{r}P \text { Value } \\
0.368\end{array}$} \\
\hline & 55.3 & {$[11.2]$} & 55.1 & [10.9] & & 53.9 & {$[11.3]$} & $53.0 \quad[10.0]$ & \\
\hline Age categories, \% (n) & & & & & 0.086 & & & & 0.061 \\
\hline $18-34$ & 4.3 & (14) & 2.4 & (29) & & 6.0 & (8) & (20) & \\
\hline $35-44$ & 8.9 & (29) & 13.8 & $(165)$ & & 11.2 & $(15)$ & $16.4 \quad(106)$ & \\
\hline $45-54$ & 34.5 & $(112)$ & 31.3 & $(374)$ & & 36.6 & $(49)$ & (233) & \\
\hline $55-64$ & 34.5 & $(112)$ & 35.9 & $(429)$ & & 28.4 & $(38)$ & $33.4 \quad(216)$ & \\
\hline $65-74$ & 11.7 & (38) & 11.6 & (139) & & 14.2 & (19) & $9.4 \quad(61)$ & \\
\hline $75+$ & 6.2 & (20) & 4.9 & (59) & & 3.7 & (5) & (10) & \\
\hline Sex, \% (n) & & & & & 0.206 & & & & 0.266 \\
\hline Male & 56.0 & $(182)$ & 52.1 & $(622)$ & & 53.7 & $(72)$ & (313) & \\
\hline Female & 44.0 & (143) & 47.9 & (573) & & 46.3 & $(62)$ & (333) & \\
\hline Geographic region, \% (n) & & & & & 0.250 & & & & 0.906 \\
\hline Northeast & 21.2 & $(69)$ & 23.2 & $(277)$ & & 23.1 & $(31)$ & $(146)$ & \\
\hline North Central & 17.8 & $(58)$ & 16.8 & $(201)$ & & 18.7 & $(25)$ & $(124)$ & \\
\hline South & 45.8 & (149) & 45.9 & $(548)$ & & 44.8 & $(60)$ & $44.3 \quad(286)$ & \\
\hline West & 12.9 & $(42)$ & 13.4 & $(160)$ & & 11.2 & $(15)$ & $12.7 \quad(82)$ & \\
\hline Unknown & 2.2 & $(7)$ & 0.8 & (9) & & 2.2 & (3) & 1.2 & \\
\hline Insurance plan type, \% (n) & & & & & 0.091 & & & & 0.954 \\
\hline Basic/major medical & 0.0 & $(0)$ & 0.0 & $(0)$ & & 0.0 & $(0)$ & 0.0 & \\
\hline Comprehensive & 8.6 & $(28)$ & 10.6 & $(127)$ & & 9.0 & $(12)$ & $(56)$ & \\
\hline Exclusive provider organization & 0.0 & $(0)$ & 0.8 & (10) & & 0.0 & $(0)$ & 0.6 & \\
\hline Health maintenance organization & 14.2 & (46) & 11.8 & (141) & & 13.4 & (18) & 11.3 & \\
\hline Point of service & 9.2 & (30) & 11.5 & (137) & & 11.2 & $(15)$ & 12.4 & \\
\hline Preferred provider organization & 57.5 & $(187)$ & 51.0 & $(610)$ & & 54.5 & $(73)$ & $(334)$ & \\
\hline Point of service with capitation & 0.6 & (2) & 2.0 & (24) & & 0.7 & (1) & (13) & \\
\hline Consumer-directed health plan & 4.6 & (15) & 5.7 & $(68)$ & & 5.2 & $(7)$ & (37) & \\
\hline High deductible health plan & 2.2 & $(7)$ & 1.7 & $(20)$ & & 2.2 & (3) & $(12)$ & \\
\hline Unknown & 3.1 & $(10)$ & 4.9 & $(58)$ & & 3.7 & $(5)$ & $(37)$ & \\
\hline Population density, \% (n) & & & & & 0.402 & & & & 0.972 \\
\hline Urban & 78.8 & $(256)$ & 80.2 & (958) & & 79.1 & (106) & $(513)$ & \\
\hline Rural & 19.7 & (64) & 19.1 & $(228)$ & & 19.4 & (26) & $(125)$ & \\
\hline Unknown & 1.5 & (5) & 0.8 & (9) & & 1.5 & (2) & 1.2 & \\
\hline Payer, \% (n) & & & & & 0.452 & & & & 0.023 \\
\hline Commercial & 81.2 & $(264)$ & 83.0 & $(992)$ & & 81.3 & (109) & $88.5 \quad(572)$ & \\
\hline Medicare & 18.8 & (61) & 17.0 & (203) & & 18.7 & $(25)$ & $11.5 \quad(74)$ & \\
\hline
\end{tabular}

a Sample restricted to patients with $B M I \geq 30$ and no evidence of previous cardiovascular disease.

${ }^{b}$ Weight gain = increase in weight by $>3 \%$; nonweight gain $=$ weight gain $\leq 3 \%$ and weight loss.

$B M I=$ body mass index; $S D=$ standard deviation.

Patients were required to have $\geq 1$ weight measurement within 45 days before to 14 days after the index date (baseline weight), and $\geq 1$ weight measurement approximately 6 months later (within 135 to 225 days after the index date; follow-up weight). In addition, $\geq 1$ blood pressure and $\geq 1$ hemoglobin (Alc) measurement were required in the period spanning 45 days before to 14 days after the index date, as well as at any point on or after the follow-up weight measurement.
For the subgroup of obese patients with no previous CVD, patients were required to have BMI information available in their medical records, be classified as obese using the baseline weight $\left(\mathrm{BMI} \geq 30 \mathrm{~kg} / \mathrm{m}^{2}\right),{ }^{21}$ and have no medical claims with a diagnosis for CVD-defined as $\geq 1$ medical claim with a diagnosis or procedure (where applicable) listed in the "Cardiovascular disease" section of Appendix A-during the baseline period. Within this subgroup, patients were also excluded if they had $\geq 1$ medical claim with a diagnosis of 
TABLE 2 Patient Baseline Clinical Characteristics

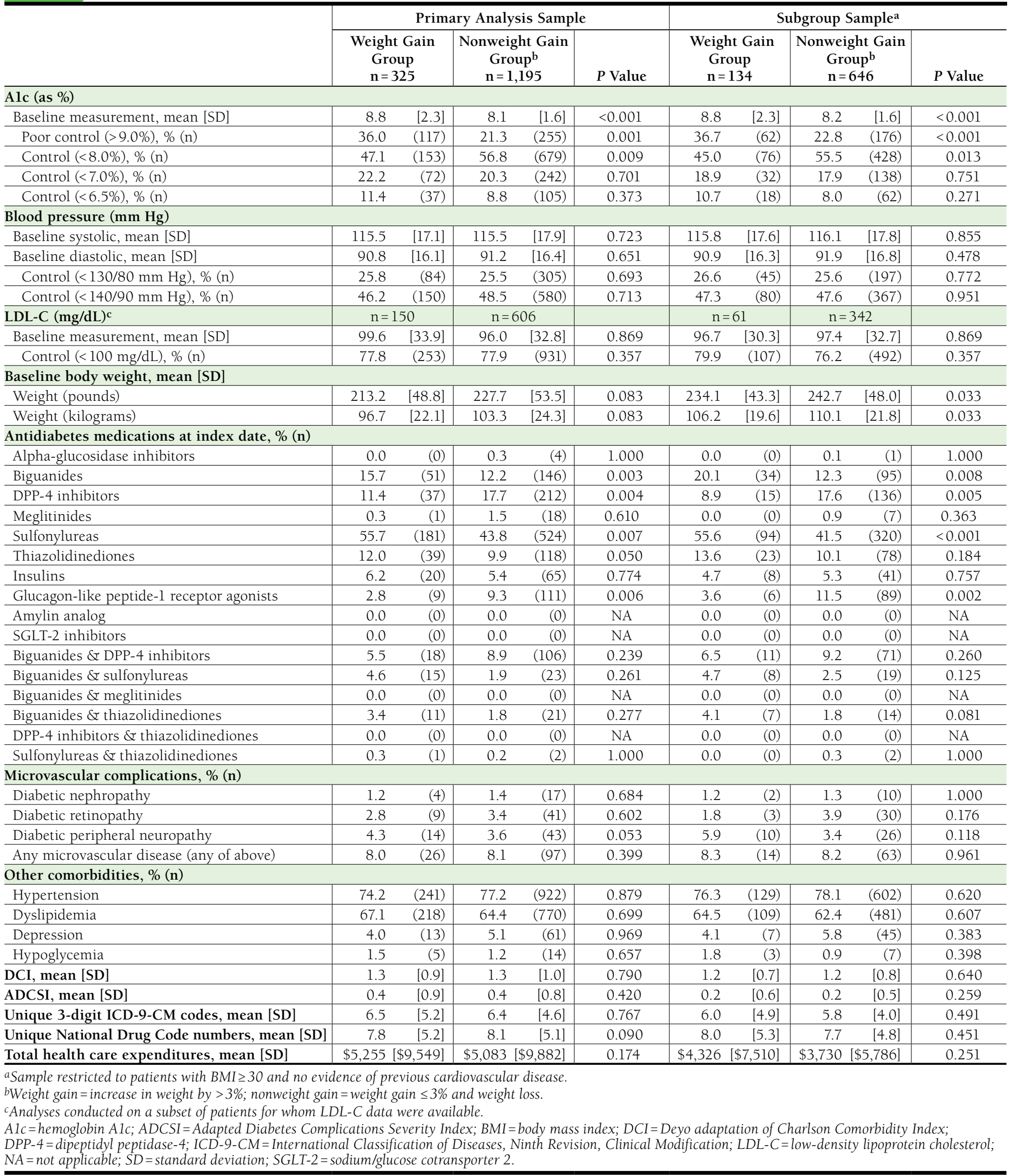


cancer (except for nonmelanoma skin cancer) during the baseline or follow-up periods.

\section{Measurement of Primary Independent Variable}

The primary independent variable of interest was percentage weight change (PWC) between the baseline weight and the follow-up weight. PWC could range from negative (weight loss) to positive (weight gain). For the purposes of descriptive reporting only, patients were categorized according to whether their PWC indicated (a) weight gain $>3 \%$, or (b) nonweight gain, which included weight gain $\leq 3 \%$ and weight loss. ${ }^{22}$

\section{Measurement of Study Outcomes}

Beginning on the date of the follow-up weight measurement, patients' data for the subsequent 12-month period (outcomes follow-up period) were evaluated to collect information on the study outcomes. Thus, the period during which the PWC was assessed was temporally precedent to the period during which the study outcomes were assessed.

Measurement of NCQA/HEDIS Comprehensive Diabetes Care Outcomes. The NCQA/HEDIS Comprehensive Diabetes Care outcomes of primary interest were 3 individual measures of Alc control (poor control [>9.0\%], control $[<8.0 \%]$, and control $[<7.0 \%]$ ) and 2 individual measures of blood pressure control (control $[<130 / 80 \mathrm{~mm} \mathrm{Hg}]$ and control $[<140 / 90 \mathrm{~mm}$ $\mathrm{Hg}$ ). A measure of low-density lipoprotein cholesterol (LDL-C) control $(<100 \mathrm{mg} / \mathrm{dL})$ was examined in the subset of patients for whom LDL-C data were available. Finally, a more stringent measure of Alc control $(<6.5 \%)$ was also examined, since it is advocated by the ADA as a reasonable goal for selected patients. ${ }^{23}$ Consistent with the NCQA/HEDIS specifications, the first available clinical measure that occurred in the outcomes follow-up period was used for analysis.

Measurement of Health Care Cost Outcomes. All-cause health care costs were measured based on all outpatient pharmacy claims and all inpatient and outpatient medical claims incurred during the outcomes follow-up period. Diabetesspecific costs were measured based on outpatient pharmacy claims for antidiabetes drugs and inpatient and outpatient medical claims with a diagnosis of T2DM (ICD-9-CM 250. $\mathrm{x} 0$ and 250.x2) in any diagnosis position incurred during the outcomes follow-up period. . $4-26^{2}$

For the all-cause and the diabetes-specific classifications, health care costs were measured for the following mutually exclusive and exhaustive settings of care: inpatient admissions, emergency room (ER) visits, outpatient office visits and services, and pharmacy. The previously mentioned settings of care were distinguished based on place of service, by which the MarketScan databases are organized and classified. Health care costs were expressed in 2013 constant dollars, adjusted using the medical care component of the Consumer Price Index. ${ }^{27}$
Health care costs included the gross covered payments for all health care services or products, including the patients' and the payers' portions of payment.

\section{Measurement of Patient Demographic and Clinical Characteristics}

Patient demographics and clinical characteristics measured for this study are listed in Tables 1 and 2. Demographics were measured as of the index date based on insurance enrollment records. Clinical characteristics were measured during the baseline period. Comorbidities were identified based on the presence of $\geq 1$ medical claim with an ICD-9-CM diagnosis of interest recorded in any diagnosis position. To reduce the potential for false positives, medical claims associated with services that may be used in the process to rule out conditions (e.g., laboratory claims or radiology claims) were not considered when searching for diagnoses. Medications were identified based on the presence of $\geq 1$ outpatient pharmacy claim for the medication of interest. Several indices of health status were measured based on medical claims, including the Deyo adaptation of the Charlson Comorbidity Index, the Adapted Diabetes Complications Severity Index, count of unique 3-digit ICD-9-CM diagnosis codes, count of unique NDC numbers, and total health care expenditures. ${ }^{28-30}$

\section{Statistical Analyses}

Bivariate analyses were used to descriptively summarize patient demographics, baseline clinical characteristics, and outcomes, stratifying patients by the weight gain and nonweight gain groups. To understand whether patient characteristics differed between the descriptive stratifications, chi-square tests were used to test for statistically significant differences in categorical variables between the cohorts, and t-tests were used to test for statistically significant differences in continuous variables. Hypothesis testing was not completed for the unadjusted analyses of outcomes.

Multivariable generalized linear models were used to examine the adjusted association between a 1 percentage point decrease in PWC (weight loss) and the study outcomes. Models examining the clinical outcomes, all of which were binary, used a logit link and binomial distribution. Models examining health care costs used a log link and gamma distribution. All models adjusted for the following a priori defined specification of covariates: baseline Alc, baseline weight, baseline blood pressure <140/90 mm Hg, commercial insurance (vs. Medicare supplemental), index year, age category, population density, health plan type, geographic region of residence, sex, baseline or follow-up cancer diagnosis (not included in subanalyses), and baseline clinical characteristics including the Deyo adaptation of the Charlson Comorbidity Index, Adapted Diabetes Complications Severity Index, count of unique 3-digit ICD-9-CM diagnosis codes, count of unique NDC numbers, inpatient stay, ER visit, general practitioner 


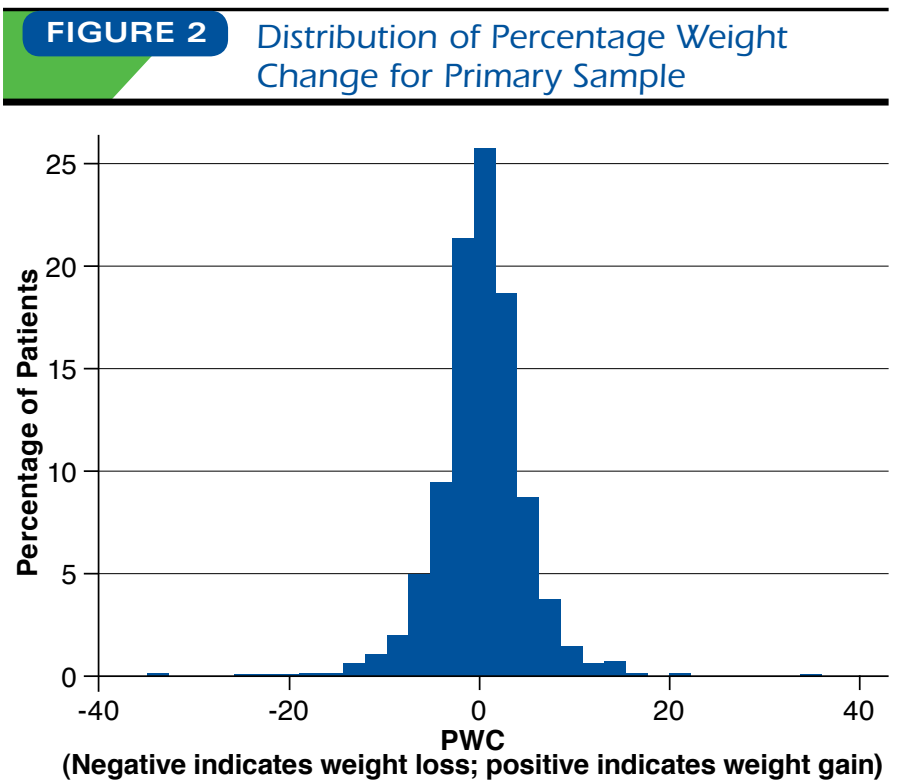

PWC = percentage weight change.

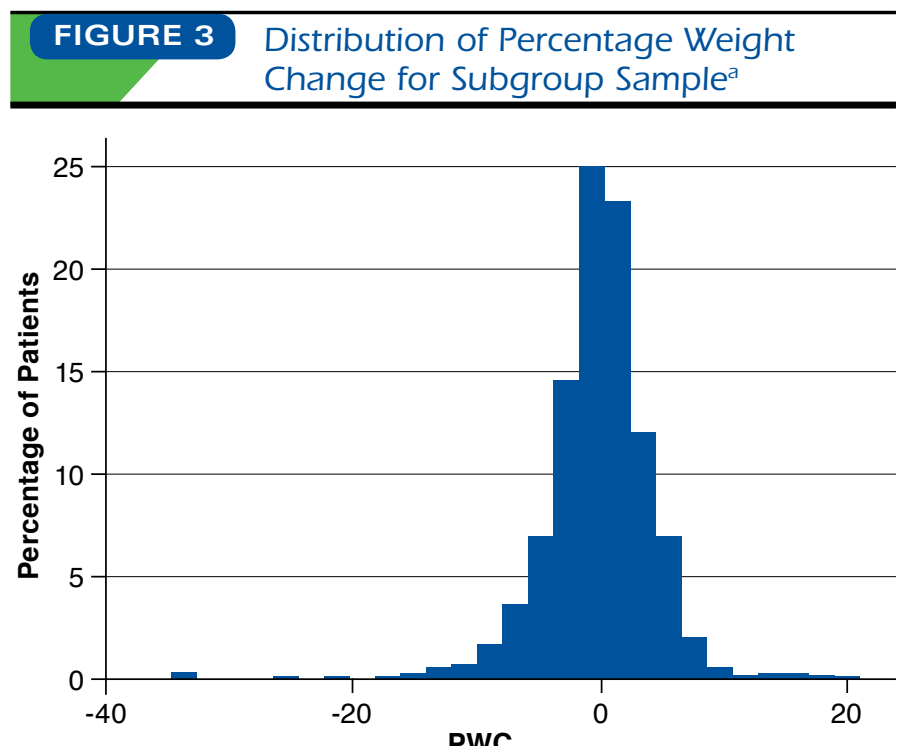

(Negative indicates weight loss; positive indicates weight gain)

a Sample restricted to patients with $B M I \geq 30$ and no evidence of previous cardiovascular disease

$B M I=$ body mass index; $P W C=$ percentage weight change .

measurement taken approximately 6 months after the baseline measurement, the mean [SD] absolute change in weight from baseline was -0.09 [11.1] lbs $(-0.04$ [5.0] kg), translating to a mean [SD] PWC of $0.2 \%$ [4.7\%] for the primary analysis sample and -0.7 [11.8] lbs $(-0.32[5.3] \mathrm{kg})$, translating to a mean [SD] PWC of $-0.2 \%[4.6 \%]$ for the subgroup sample.

In both samples, demographics were generally similar between the weight gain and nonweight gain groups (Table 1). In both samples, mean baseline Alc was higher among the weight gain versus nonweight gain groups (Table 2). Compared with weight gain groups, a lower proportion of patients in the nonweight gain groups were taking sulfonylureas at index or metformin at index (Table 2); conversely, compared with weight gain groups, a higher proportion of patients in the nonweight gain groups were taking dipeptidyl peptidase-4 inhibitors at index or glucagon-like peptide-1 receptor agonists at index. Other clinical characteristics were generally similar across the groups (Table 2).

\section{NCOA/HEDIS Comprehensive Diabetes Care Outcomes in 12-Month Outcomes Follow-up Period}

In adjusted analyses, decreasing PWC (weight loss) was associated with increasing odds of attaining the Alc goals of $<6.5 \%$ $(P<0.001)$ and $<7.0 \% \quad(P<0.001)$ in the primary analysis sample and increasing odds of attaining the Alc goals of $<6.5 \%$ $(P<0.001),<7.0 \%(P<0.001)$, and $<8.0 \%(P=0.010)$ in the subgroup sample (Table 3). PWC was not associated with LDL-C or blood pressure in the primary or subgroup samples. 
TABLE 3 Adjusted NCQA/HEDIS Comprehensive Diabetes Care and Clinical Outcomes During Outcomes Follow-up Period

\begin{tabular}{|c|c|c|c|c|c|c|}
\hline & \multirow[b]{3}{*}{ Adjusted Effect Estimate ${ }^{a}$} & \multicolumn{5}{|c|}{ Adjusted Predicted Probabilities, ${ }^{\mathrm{b}} \%$} \\
\hline & & \multicolumn{5}{|c|}{ PWC } \\
\hline & & $-5 \%$ & $-2.5 \%$ & $0 \%$ & $2.5 \%$ & $5 \%$ \\
\hline \multicolumn{7}{|l|}{ Primary analysis sample } \\
\hline \multicolumn{7}{|l|}{ Alc (as \%), $\mathrm{n}=1,520$} \\
\hline Poor control (>9.0) & $\mathrm{OR}=0.99 \quad(95 \% \mathrm{CI}=0.95-1.03) \quad P=0.660$ & NS & NS & NS & NS & NS \\
\hline Control $(<8.0)$ & $\mathrm{OR}=1.02 \quad(95 \% \mathrm{CI}=0.99-1.05) \quad P=0.240$ & NS & NS & NS & NS & NS \\
\hline Control $(<7.0)$ & $\mathrm{OR}=1.05(95 \% \mathrm{CI}=1.03-1.09) \quad \mathrm{P}<0.001$ & 58.8 & 55.9 & 52.8 & 49.8 & 46.7 \\
\hline Control $(<6.5)$ & $\mathrm{OR}=1.08 \quad(95 \% \mathrm{CI}=1.05-1.11) \quad P<0.001$ & 43.1 & 39.0 & 35.1 & 31.3 & 27.8 \\
\hline \multicolumn{7}{|c|}{ Blood pressure $(\mathrm{mm} \mathrm{Hg}), \mathrm{n}=1,520$} \\
\hline Control $(<130 / 80 \mathrm{~mm} \mathrm{Hg})$ & $\mathrm{OR}=1.01 \quad(95 \% \mathrm{CI}=0.99-1.04) \quad P=0.380$ & NS & NS & NS & NS & NS \\
\hline Control $(<140 / 90 \mathrm{~mm} \mathrm{Hg})$ & $\mathrm{OR}=1.00(95 \% \mathrm{CI}=0.98-1.03) \quad P=0.700$ & NS & NS & NS & NS & NS \\
\hline \multicolumn{7}{|l|}{ LDL-C (mg/dL), $n=756^{c}$} \\
\hline Control $(<100 \mathrm{mg} / \mathrm{dL})$ & $\mathrm{OR}=1.02 \quad(95 \% \mathrm{CI}=0.99-1.06) \quad P=0.210$ & NS & NS & NS & NS & NS \\
\hline \multicolumn{7}{|l|}{ Subgroup sampled } \\
\hline \multicolumn{7}{|l|}{ Alc (as \%), $n=780$} \\
\hline Poor control (>9.0) & $\mathrm{OR}=0.96(95 \% \mathrm{CI}=0.90-1.03) \quad P=0.250$ & NS & NS & NS & NS & NS \\
\hline Control $(<8.0)$ & $\mathrm{OR}=1.08 \quad(95 \% \mathrm{CI}=1.02-1.14) \quad P=0.010$ & 86.6 & 84.8 & 82.8 & 80.7 & 78.3 \\
\hline Control $(<7.0)$ & $\mathrm{OR}=1.11 \quad(95 \% \mathrm{CI}=1.06-1.15) \quad P<0.001$ & 63.2 & 57.9 & 52.5 & 47.1 & 41.7 \\
\hline Control $(<6.5)$ & $\mathrm{OR}=1.09(95 \% \mathrm{CI}=1.04-1.12) \quad P<0.001$ & 43.9 & 39.8 & 35.8 & 32.0 & 28.3 \\
\hline \multicolumn{7}{|c|}{ Blood pressure $(\mathrm{mm} \mathrm{Hg}), \mathrm{n}=780$} \\
\hline Control $(<130 / 80 \mathrm{~mm} \mathrm{Hg})$ & $\mathrm{OR}=0.98 \quad(95 \% \mathrm{CI}=0.94-1.02) \quad P=0.410$ & NS & NS & NS & NS & NS \\
\hline Control $(<140 / 90 \mathrm{~mm} \mathrm{Hg})$ & $\mathrm{OR}=0.97 \quad(95 \% \mathrm{CI}=0.94-1.01) \quad P=0.144$ & NS & NS & NS & NS & NS \\
\hline \multicolumn{7}{|l|}{ LDL-C (mg/dL), $\mathrm{n}=403^{\mathrm{c}}$} \\
\hline Control $(<100 \mathrm{mg} / \mathrm{dL})$ & $\mathrm{OR}=1.03 \quad(95 \% \mathrm{CI}=0.97-1.09) \quad P=0.287$ & NS & NS & NS & NS & NS \\
\hline \multicolumn{7}{|c|}{$\begin{array}{l}\text { aAssociation between } 1 \text { percentage point decrease in PWC and outcome. } \\
\text { bAdjusted predicted probabilities of attaining Alc goals calculated for outcomes with which the PWC was significantly associated. } \\
\text { cAnalyses conducted on a subset of patients for whom LDL-C data were available. } \\
\text { dSample restricted to patients with BMI } \geq 30 \text { and no evidence of previous cardiovascular disease. } \\
\text { Alc=hemoglobin Alc; BMI = body mass index; CI = confidence interval; } L D L-C=\text { low-density lipoprotein cholesterol; NCQA/HEDIS=National Committee for Quality } \\
\text { Assurance/Healthcare Effectiveness Data and Information Set; NS=not significant; OR=odds ratio; } P W C=\text { percentage weight change. }\end{array}$} \\
\hline
\end{tabular}

The adjusted predicted probabilities of attaining the Alc goals with which the PWC was significantly associated are displayed in Table 3 for varying levels of the PWC in the primary and subgroup samples. For example, in the primary analysis sample, the adjusted predicted probability of attaining the Alc goal of $<6.5 \%$ as of the first Alc measurement during the outcomes follow-up period was $39.0 \%$ for a PWC of $-2.5 \%, 35.1 \%$ for a PWC of $0 \%$, and $31.3 \%$ for a PWC of $2.5 \%$ (Table 3). Unadjusted results are presented in Appendix B (available in online article).

\section{Health Care Cost Outcomes in 12-Month Outcomes Follow-up Period}

In adjusted analyses, decreasing PWC (weight loss) was associated with decreasing diabetes-specific pharmacy costs $(P<0.001)$ in the primary analysis sample and with decreasing all-cause pharmacy costs $(P=0.018)$, diabetes-specific total costs $(P=0.039)$, diabetes-specific medical costs $(P=0.002)$, and diabetes-specific pharmacy costs $(P<0.001)$ in the sub-group sample (Table 4). PWC was not associated with all-cause total health care costs or all-cause medical costs in either sample.
The adjusted predicted health care costs with which the PWC was significantly associated are displayed in Table 4 for varying levels of the PWC in the primary and subgroup samples. For example, in the subgroup sample, adjusted mean predicted per-patient diabetes-specific total health care costs during the 12-month outcomes follow-up period were $\$ 4,448$ for a PWC of $-2.5 \%, \$ 4,804$ for a PWC of $0 \%$, and $\$ 5,189$ for a PWC of 2.5\%. Unadjusted results are presented in Appendices $\mathrm{C}$ and $\mathrm{D}$ (available in online article).

\section{Discussion}

This study examined the association between weight change, health care costs, and various clinical outcomes among patients with T2DM, who, as of the index date, had specifically added to or switched treatment from metformin. This study also examined a subgroup of patients who were obese and had no previous CVD. In the primary analysis sample and the subgroup sample, decreasing PWC was found to be significantly associated with increasing odds of attaining several common Alc goals $(P<0.001$ for Alc $<7.0$ and Alc $<6.5$ in the primary analysis 


\begin{tabular}{|c|c|c|c|c|c|c|}
\hline & \multirow[b]{3}{*}{ Adjusted Effect Estimate ${ }^{a}$} & \multicolumn{5}{|c|}{ Adjusted Predicted Costs, Mean $\$$ b } \\
\hline & & \multicolumn{5}{|c|}{ PWC } \\
\hline & & $-5 \%$ & $-2.5 \%$ & $0 \%$ & $2.5 \%$ & $5 \%$ \\
\hline \multicolumn{7}{|c|}{ Primary analysis sample } \\
\hline \multicolumn{7}{|c|}{ All-cause, $\mathrm{n}=1,520$} \\
\hline Medical & $\mathrm{CR}=1.00(95 \% \mathrm{CI}=0.98-1.02) \quad P=0.920$ & NS & NS & NS & NS & NS \\
\hline Pharmacy & $\mathrm{CR}=0.99(95 \% \mathrm{CI}=0.98-1.01) \quad P=0.280$ & NS & NS & NS & NS & NS \\
\hline Total & $\mathrm{CR}=1.00 \quad(95 \% \mathrm{CI}=0.98-1.02) \quad P=0.950$ & NS & NS & NS & NS & NS \\
\hline \multicolumn{7}{|c|}{ Diabetes-specific, $\mathrm{n}=1,520$} \\
\hline Medical & $\mathrm{CR}=0.99 \quad(95 \% \mathrm{CI}=0.96-1.03) \quad P=0.760$ & NS & NS & NS & NS & NS \\
\hline Pharmacy & $\mathrm{CR}=0.97 \quad(95 \% \mathrm{CI}=0.96-0.99) \quad P<0.001$ & 1,141 & 1,224 & 1,312 & 1,406 & 1,507 \\
\hline Total & $\mathrm{CR}=0.99(95 \% \mathrm{CI}=0.96-1.01) \quad P=0.350$ & NS & NS & NS & NS & NS \\
\hline \multicolumn{7}{|c|}{ Subgroup samplec } \\
\hline \multicolumn{7}{|c|}{ All-cause, $n=780$} \\
\hline Medical & $\mathrm{CR}=0.99(95 \% \mathrm{CI}=0.96-1.02) \quad P=0.586$ & NS & NS & NS & NS & NS \\
\hline Pharmacy & $\mathrm{CR}=0.98 \quad(95 \% \mathrm{CI}=0.96-0.996) P=0.018$ & 4,302 & 4,567 & 4,848 & 5,147 & 5,464 \\
\hline Total & $\mathrm{CR}=0.99 \quad(95 \% \mathrm{CI}=0.96-1.01) \quad P=0.209$ & NS & NS & NS & NS & NS \\
\hline \multicolumn{7}{|c|}{ Diabetes-specific, $n=780$} \\
\hline Medical & $\mathrm{CR}=0.97(95 \% \mathrm{CI}=0.94-0.998) P=0.030$ & 3,096 & 3,340 & 3,603 & 3,887 & 4,193 \\
\hline Pharmacy & $\mathrm{CR}=0.97 \quad(95 \% \mathrm{CI}=0.95-0.99) \quad P=0.002$ & 1,208 & 1,317 & 1,436 & 1,565 & 1,706 \\
\hline Total & $\mathrm{CR}=0.96(95 \% \mathrm{CI}=0.95-0.98) \quad P<0.001$ & 4,118 & 4,448 & 4,804 & 5,189 & 5,604 \\
\hline \multicolumn{7}{|c|}{$\begin{array}{l}\text { aAssociation between } 1 \text { percentage point decrease in } P W C \text { and outcome. } \\
\text { bAdjusted predicted costs calculated for outcomes with which the } P W C \text { was significantly associated. } \\
\text { cSample restricted to patients with } B M I \geq 30 \text { and no evidence of previous cardiovascular disease. } \\
\text { BMI= body mass index; } C I=\text { confidence interval; } C R=\text { cost ratio; } N S=\text { not significant; } P W C=\text { percentage weight change. }\end{array}$} \\
\hline
\end{tabular}

sample and subgroup sample; $P=0.01$ for Alc $<8.0$ in the subgroup sample). Although decreasing PWC was generally associated with decreasing all-cause and diabetes-specific health care costs, this association reached statistical significance in the primary analysis sample for diabetes-specific pharmacy costs $(P<0.001)$. In the subgroup sample, the association was stronger, reaching statistical significance for all-cause pharmacy costs $(P=0.018)$ and diabetes-specific medical $(P=0.030)$, pharmacy $(P=0.002)$, and total costs $(P<0.001)$.

To our knowledge, 4 published observational studies have quantified the association between general weight change (i.e., not necessarily resulting from an intervention) and health care utilization and/or costs among patients with T2DM. Yu et al. (2007) analyzed data from 458 U.S. patients with T2DM and reported that 1 percentage point of weight loss over a 6 -month period was associated with a $3.6 \%$ decrease in total health care costs and a $5.8 \%$ decrease in diabetes-specific health care costs in the subsequent year. ${ }^{9}$ Consistent with the present study's findings of more pronounced effects of PWC among the subgroup sample of obese patients, Yu et al. found a statistically significant $6.7 \%(P<0.01)$ reduction in diabetes-specific health care costs in obese patients versus a nonstatistically significant 3.5\% reduction in nonobese patients. ${ }^{9}$ Dilla et al. (2012) analyzed self-reported clinical and economic data collected from 738 Spanish patients with T2DM and reported that over a 1-year period, a 1-unit gain in BMI was associated with a $20.0 \%$ increase in estimated costs during the same period among BMI gainers, while a 1-unit loss in BMI was associated with an $8.0 \%$ decrease in costs among non-BMI gainers. ${ }^{8}$ Dilla et al. also found more pronounced effects of weight change among patients who were obese, with a 1-unit reduction in BMI associated with a 9.4\% decrease in health care costs among obese patients versus $2.7 \%$ in nonobese patients. ${ }^{8}$ Bell et al. (2014) analyzed data from 2,110 patients with T2DM and reported significant associations between weight change over a 6-month period and all-cause total health care costs in the subsequent year but, unlike the present study, found no associations between weight change and all-cause and diabetesspecific pharmacy costs. ${ }^{7}$ Finally, Davis et al. (2011) analyzed data on 590 Australian patients with T2DM and reported that weight loss $\geq 5 \%$ of initial body weight versus weight loss $<5 \%$ of initial body weight or weight gain over a mean 4.3-year period was associated with an AUD $\$ 100$ decrease in diabetes medication costs. ${ }^{10}$

Thresholds of Alc $<7 \%$ (and $<6.5 \%$ for select patients) are the primary means to evaluate achievement of glycemic goals among patients with T2DM. ${ }^{23}$ Observed weight loss was associated with a higher likelihood of achievement of these glycemic goals in the primary population and the subgroup sample (all with $P<0.001$ in the primary analysis sample and subgroup 
sample). These results confirm of the direct impact of moderate weight change on key clinical outcomes for diabetes found in previous research..$^{1-4,33}$

Associations between PWC and blood pressure or LDL-C were not observed in either of the samples. Such associations might not be expected in the subgroup sample because these individuals did not have evidence of CVD, which is strongly associated with these measures. A lack of observed association overall may also be due to the relatively short window of time over which the weight change and clinical outcomes were measured and may suggest that relatively moderate amounts of weight change do not have the same impact on blood pressure or LDL-C as on Alc.

A multifactorial approach to diabetes care in individuals with CVD includes glucose control, blood pressure management, aspirin therapy, and lipid management with statins, which have been shown to reduce vascular complications and cardiovascular mortality. ${ }^{34}$ Weight loss, as well as diabetes management, are currently considered after other priorities in the secondary prevention recommendations for individuals with CVD. ${ }^{35-37}$ Thus, in view of guidelines and the findings of the Look AHEAD study, ${ }^{16}$ a subpopulation of patients who were obese and had no previous CVD was examined. Given that most of the outcomes observed in this subgroup were favorable, it appears that weight management in a population of patients with T2DM in which primary prevention of CVD is possible may provide more benefit than in a secondary prevention population. Furthermore, the benefits of weight loss in reducing health care costs in patients with T2DM and established CVD may be difficult to detect because such patients may have other comorbidities that are not influenced by weight change and because CVD is a powerful determinant of health care costs. ${ }^{38}$ In both cohorts, associations between weight loss and decreased costs were observed for health care costs that were diabetes specific. All-cause costs may be driven by multiple factors, including the management of T2DM as well as any variety of comorbidities. It is therefore possible that, in the relatively short term, small amounts of weight change, such as the amount observed in the present study, most strongly impact costs directly related to diabetes care. However, these costs are of great importance, since costs due to diabetes and diabetesrelated complications represent a substantial and increasing economic burden to society. ${ }^{39}$

Taken together with previous research highlighting the favorable association between weight loss, health care costs, and Alc, ${ }^{7-10}$ the present study adds to a body of knowledge that may have implications for clinical practice. If moderate changes in weight impact health care costs and Alc among patients with T2DM to the extent observed in this study, a focus on weight change early on in the disease course may be warranted. Thus, patients with T2DM may benefit from earlier lines of therapy that are driven not only by glycemic efficacy but also by weight change properties. As outlined in the ADA and EASD guidelines for the management of hyperglycemia in T2DM, weight change properties vary widely across available antidiabetic medication classes. ${ }^{12}$ For example, among the antidiabetic medications that are most commonly used in the United States, sulfonylureas, thiazolidinediones, and insulins are associated with weight gain; biguanides (metformin) and dipeptidyl peptidase 4 inhibitors are weight neutral; and glucagon-like peptide-1 receptor agonists and sodium-glucose co-transporter 2 inhibitors are associated with weight loss. ${ }^{12}$

\section{Limitations}

The results of this study must be interpreted in light of the study's limitations. First, the study data do not allow us to understand the source of weight change, which could be related to a broad range of factors, such as patient lifestyle modifications (including diet and exercise), comorbidity, or the weight change properties of the antidiabetes medications that patients were taking. Future research to identify any heterogeneity in the impact of weight loss based on source would be useful in understanding the potential relative values of different weight loss strategies.

Second, administrative claims, EMR, and laboratory records are subject to coding inaccuracies, which can introduce measurement error into the study variables. Despite this, it is unlikely that such coding errors would vary systematically by the PWC. Third, the average duration of diabetes was unknown, so the relative effects of weight change early or late in the disease process could not be evaluated.

Fourth, the PWC was measured over a relatively short period of 6 months after the addition of or switch to a nonmetformin antidiabetes medication. Because this period immediately follows a change to a patient's antidiabetes medication regimen, it may be relatively unstable with respect to treatment adjustments and the level of interaction that a patient has with health care providers. However, during this 6-month period of time, the interquartile range of the PWC was relatively narrow at $-2.2 \%$ to $2.2 \%$. Therefore, the results may not be generalizable to longer periods of time or larger gains or losses in weight. Furthermore, the results of this study do not reflect the impact of changes in weight that may or may not be sustained over long periods of time. In a recent study presented by Sabale et al. (2015), initial (1-year) weight gain in Swedish patients who were newly diagnosed with T2DM generally led to longerterm (3-year) increased health care costs even when the initial weight loss was not necessarily sustained. ${ }^{40}$ Overall, the results of this study suggest that weight changes of only a few percentage points during this short period can be associated with several hundreds of dollars in diabetes-specific health care cost increases or decreases.

Fifth, diabetes-specific cost estimates in this study did not specifically include diabetes supplies, some of which may be paid for out of pocket and which have previously been 
estimated to represent approximately $1 \%$ of diabetes-specific costs in patients with T2DM in $2007 .^{41}$ Sixth, this study sample was drawn from a broader nonprobability sample and, while larger than those of some similar previous studies, may not be broadly generalizable to the entire U.S. population or individuals in other countries.

\section{Conclusions}

This real-world study suggests that among patients with T2DM who had specifically added to or switched treatment from metformin, subsequent weight loss over a short-term (6-month) period was associated with positive impact on attainment of Alc goals and decreased diabetes-specific pharmacy costs over the following 12 months. In the subset of patients who were obese and had no previous CVD, short-term weight loss over the 6-month period was also associated with decreased all-cause pharmacy costs, diabetes-specific medical costs, and diabetes-specific total health care costs. Future research is longer-term follow-up periods.

\section{Authors}

JAYANTI MUKHERJEE, PhD, Bristol-Myers Squibb, Wallingford, Connecticut; CATARINA STERNHUFVUD, MSc, AstraZeneca, Mölndal, Sweden; NANCY SMITH, MS, Bristol-Myers Squibb, Princeton, New Jersey; and KELLY BELL, PharmD, MSPhr, AstraZeneca, Fort Washington, Pennsylvania. MARNI STOTTMILLER, PhD; DONNA MCMORROW, BS; and STEPHEN JOHNSTON, MA, Truven Health Analytics, Bethesda, Maryland.

AUTHOR CORRESPONDENCE: Stephen Johnston, MA, 7700 Old Georgetown Rd., Ste. 650, Bethesda, MD 20814. Tel.: 443.254.2222; Fax: 301.547.4690;

E-mail: stephen.johnston@truvenhealth.com. warranted to examine whether these associations change over

2. McAdam-Marx C, Bellows BK, Unni S, et al. Determinants of glycaemic control in a practice setting: the role of weight loss and treatment adherence (The DELTA Study). Int J Clin Pract. 2014;68(11):1309-17.

3. McAdam-Marx C, Mukherjee J, Bellows BK, et al. Evaluation of the relationship between weight change and glycemic control after initiation of antidiabetes therapy in patients with type 2 diabetes using electronic medical record data. Diabetes Res Clin Pract. 2014;103(3):402-11.

4. McAdam-Marx C, Bellows BK, Unni S, et al. Impact of adherence and weight loss on glycemic control in patients with type 2 diabetes: cohort analyses of integrated medical record, pharmacy claims, and patient-reported data. J Manag Care Spec Pharm. 2014;20(7):691-700. Available at: http:// www.jmcp.org/doi/abs/10.18553/jmcp.2014.20.7.691.

5. Fox CS, Pencina MJ, Wilson PW, Paynter NP, Vasan RS, D'Agostino RB Sr. Lifetime risk of cardiovascular disease among individuals with and without diabetes stratified by obesity status in the Framingham heart study. Diabetes Care. 2008;31(8):1582-84.

6. Eeg-Olofsson K, Cederholm J, Nilsson PM, et al. Risk of cardiovascular disease and mortality in overweight and obese patients with type 2 diabetes: an observational study in 13,087 patients. Diabetologia. 2009;52(1):65-73.

7. Bell K, Parasuraman S, Shah M, et al. Economic implications of weight change in patients with type 2 diabetes mellitus. Am J Manag Care. 2014;20(8):e320-29.

8. Dilla T, Valladares A, Nicolay C, Salvador J, Reviriego J, Costi M. Healthcare costs associated with change in body mass index in patients with type 2 diabetes mellitus in Spain: the ECOBIM study. Appl Health Econ Health Policy. 2012;10(6):417-30.

9. Yu AP, Wu EQ, Birnbaum HG, et al. Short-term economic impact of body weight change among patients with type 2 diabetes treated with antidiabetes agents: analysis using claims, laboratory, and medical record data. Curr Med Res Opin. 2007;23(9):2157-69.

10. Davis WA, Bruce DG, Davis TM. Economic impact of moderate weight loss in patients with type 2 diabetes: the Fremantle Diabetes Study. Diabet Med. 2011;28(9):1131-35.

11. American Diabetes Association, Bantle JP, Wylie-Rosett J, et al. Nutrition recommendations and interventions for diabetes: a position statement of the American Diabetes Association. Diabetes Care. 2008;31(Suppl 1):S61-78 Available at: http://care.diabetesjournals.org/content/31/Supplement_1/S61. full.pdf+html. Accessed January 27, 2016.

12. Inzucchi SE, Bergenstal RM, Buse JB, et al. Management of hyperglycemia in type 2 diabetes: a patient-centered approach: position statement of the American Diabetes Association (ADA) and the European Association for the Study of Diabetes (EASD). Diabetes Care. 2012;35(6):1364-79.

13. Look AHEAD Research Group, Pi-Sunyer X, Blackburn G, et al. Reduction in weight and cardiovascular risk factors in individuals with type 2 diabetes: one-year results of the Look AHEAD trial. Diabetes Care. 2007;30(6)1374-83.

\section{DISCLOSURES}

This study was sponsored by AstraZeneca and Bristol-Myers Squibb. Truven Health Analytics received funding from Bristol-Myers Squibb and AstraZeneca to conduct this study. Mukherjee is an employee of Bristol-Myers Squibb. Bell and Sternhufvud are employees of AstraZeneca. Johnston, StottMiller, and McMorrow are employees of Truven Health Analytics. Nancy Smith is a consultant to Bristol-Myers Squibb and is employed by GreenKey Resources.

Study concept was created by Mukherjee, Sternhufvud, Bell, and Johnston. Stott-Miller and McMorrow took the lead in data collection, along with Johnston, with data interpretation performed by Mukherjee, Sternhufvud, Smith, Stott-Miller, and Johnston. The manuscript was written by Mukherjee, Johnston, and Stott-Miller, along with Sternhufvud and Smith, and revised by Mukherjee, Smith, and Johnston, along with Sternhufvud and Stott-Miller.

\section{REFERENCES}

1. Ross SA, Dzida G, Vora J, Khunti K, Kaiser M, Ligthelm RJ. Impact of weight gain on outcomes in type 2 diabetes. Curr Med Res Opin. 2011;27(7):1431-38.
14. Wing RR, Lang W, Wadden TA, et al. Benefits of modest weight loss in improving cardiovascular risk factors in overweight and obese individuals with type 2 diabetes. Diabetes Care. 2011;34(7):1481-86.

15. Look AHEAD Research Group, Wing RR, Bolin P, et al. Cardiovascular effects of intensive lifestyle intervention in type 2 diabetes. N Engl J Med. 2013;369(2):145-54

16. Espeland MA, Glick HA, Bertoni A, et al. Impact of an intensive lifestyle intervention on use and cost of medical services among overweight and obese adults with type 2 diabetes: the action for health in diabetes. Diabetes Care. 2014;37(9):2548-56. Available at: http://www.ncbi.nlm.nih.gov/pmc/ articles/PMC4140155/. Accessed January 27, 2016.

17. Colosia AD, Palencia R, Khan S. Prevalence of hypertension and obesity in patients with type 2 diabetes mellitus in observational studies: a systematic literature review. Diabetes Metab Syndr Obes. 2013;6:327-38. Available at: www. ncbi.nlm.nih.gov/pmc/articles/PMC3785394/. Accessed February 27, 2016.

18. Sluik D, Boeing H, Montonen J, et al. Associations between general and abdominal adiposity and mortality in individuals with diabetes mellitus. Am J Epidemiol. 2011;174(1):22-34. 
19. Song SH. Complication characteristics between young-onset type 2 versus type 1 diabetes in a UK population. BMJ Open Diabetes Res Care. 2015;3(1):e00044.

20. Zeber J, Parchman ML. Cardiovascular disease in type 2 diabetes: attributable risk due to modifiable risk factors. Can Fam Physician. 2010;56(8):e302-07.

21. Kuczmarski RJ, Flegal KM. Criteria for definition of overweight in transition: background and recommendations for the United States. Am J Clin Nutr. 2000;72(5):1074-81.

22. Stevens J, Truesdale KP, McClain JE, Cai J. The definition of weight maintenance. Int J Obes (Lond). 2006;30(3):391-99.

23. American Diabetes Association. Executive summary: standards of medical care in diabetes-2012. Diabetes Care. 2012;35(Suppl 1):S4-S10.

24. Wang L, Wei W, Miao R, Xie L, Baser O. Real-world outcomes of US employees with T2D mellitus treated with insulin glargine or neutral protamine Hagedorn insulin: a comparative retrospective database study. BMJ Open. 2013;3(4):e002348.

25. Wei W, Zhou S, Miao R, et al. Much ado about nothing? A real-world study of patients with type 2 diabetes switching basal insulin analogs. Adv Ther. 2014:31(5):539-60.

26. Meyers JL, Parasuraman S, Bell KF, Graham JP, Candrilli SD. The highcost, type 2 diabetes mellitus patient: an analysis of managed care administrative data. Arch Public Health. 2014;72(1):6

27. U.S. Bureau of Labor Statistics. Consumer Price Index detailed report tables, annual average, 2013. Available from: http://www.bls.gov/cpi/cpidl0av.pdf. Accessed January 27, 2016.

28. Deyo RA, Cherkin DC, Ciol MA. Adapting a clinical comorbidity index for use with ICD-9-CM administrative databases. J Clin Epidemiol. 1992;45(6):613-19.

29. Chang HY, Weiner JP, Richards TM, Bleich SN, Segal JB. Validating the adapted Diabetes Complications Severity Index in claims data. Am J Manag Care. 2012;18(11):721-26.

30. Fowler R, Johnston SS. Comparative performance of risk adjustment measures in a sample of commercially-insured patients under age 65-two simple measures outperform current standards. Value Health. 2010;13(3):A4 [Abstract RM1].
31. Greene WH. Econometric Analysis. 4th ed. Upper Saddle River, NJ: Prentice-Hall; 2000.

32. Kleinman LC, Norton EC. What's the risk? A simple approach for estimating adjusted risk measures from nonlinear models including logistic regression. Health Serv Res. 2009;44(1):288-302.

33. Feldstein AC, Nichols GA, Smith DH, et al. Weight change in diabetes and glycemic and blood pressure control. Diabetes Care. 2008;31(10):1960-65.

34. Gaede P, Lund-Andersen H, Parving HH, Pedersen O. Effect of a multifactorial intervention on mortality in type 2 diabetes. $N$ Engl J Med. 2008;358(6):580-91.

35. Smith SC Jr, Benjamin EJ, Bonow RO, et al. AHA/ACCF Secondary Prevention and Risk Reduction Therapy for Patients with Coronary and other Atherosclerotic Vascular Disease: 2011 update: a guideline from the American Heart Association and American College of Cardiology Foundation. Circulation. 2011;124(22):2458-73.

36. University of Michigan Health System. Guidelines for Clinical Care, Ambulatory. Secondary Prevention of Coronary Artery Disease. Updated February 2012. Available at: http://www.med.umich.edu/linfo/FHP/practiceguides/cad/cad.pdf. Accessed January 27, 2016.

37. American Diabetes Association. (8) Cardiovascular disease and risk management. Diabetes Care. 2015;38(Suppl):S49-57.

38. Nichols GA, Bell TJ, Pedula KL, O'Keeffe-Rosetti M. Medical care costs among patients with established cardiovascular disease. Am J Manag Care. 2010;16(3):e86-e93.

39. American Diabetes Association. Economic costs of diabetes in the U.S. in 2012. Diabetes Care. 2013;36(4):1033-46.

40. Sabale U, Bodegard J, Ekman M, et al. Weight change over time and its link to healthcare costs among newly-diagnosed type 2 diabetes patients in Sweden. Abstract presented at: The European Association for the Study of Diabetes 51st Annual Meeting; September 14-18, 2015; Stockholm, Sweden. [Abstract 54].

41. Dall TM, Mann SE, Zhang Y, et al. Distinguishing the economic costs associated with type 1 and type 2 diabetes. Popul Health Manag. 2009;12(2):103-10. 
APPENDIX A Study Codes and Medications ${ }^{a}$

\begin{tabular}{|c|c|c|}
\hline Condition & Type of Code & Codes \\
\hline Type 1 diabetes mellitus & ICD-9-CM diagnosis & $250 . x 1,250 . x 3$ \\
\hline Gestational diabetes & ICD-9-CM diagnosis & $648.8 \mathrm{x}$ \\
\hline \multirow[t]{4}{*}{ Pregnancy } & ICD-9-CM diagnosis & $\begin{array}{l}\text { 630.xx-648.7x, 648.9x-679.xx, V22.xx-V23.xx, V27.xx, V28.xx, V61.6x-V61.7x, } \\
\text { V72.42, V91.xx }\end{array}$ \\
\hline & ICD-9-CM procedure & 72.xx-75.xx \\
\hline & MS-DRG & $765,766,767,768,770,774,775,777,778,779$ \\
\hline & CPT & $\begin{array}{l}\text { 57022, 58605, 58611, 59000-59899, 76801-76828, 76941, 83661-83664, S0612, } \\
\text { S0613, S2400-S2405, S2409, S2411, S8055, 01965, 01966, 0500F, 0501F, 0503F }\end{array}$ \\
\hline \multirow[t]{4}{*}{ Bariatric surgery } & $\mathrm{CPT}$ & $43644,43645,43842,43843,43845,43846,43847$, S2083 \\
\hline & $\begin{array}{l}\text { ICD-9-CM procedure codes } \\
\text { ONLY IF also } 1 \text { of ICD-9-CM } \\
\text { diagnosis codes or MS-DRG } \\
\text { codes listed below }\end{array}$ & $44.95,44.96,44.97,44.98,44.38,44.68,44.31,44.39,43.82,43.89$ \\
\hline & ICD-9-CM diagnosis & $278.00,278.01, V 77.8$ \\
\hline & MS-DRG & 288 (only prior to October 1,2007 ), 619, 620, 621 \\
\hline Cancer & ICD-9-CM diagnosis & 140.xx-172.xx, 176.xx-184.xx, 188.xx-195.xx, 199.2, 200.xx-209.xx \\
\hline \multicolumn{3}{|l|}{ Cardiovascular disease } \\
\hline Atherosclerosis & ICD-9-CM diagnosis & $\begin{array}{l}440 . x x, 437.0 x, 414.0 x, 414.2 x, 414.3 x, 414.4 x, 433.00,433.10,433.20,433.30, \\
433.80,433.90\end{array}$ \\
\hline Stroke & ICD-9-CM diagnosis & 430.xx, 431.xx, 433.xl, 434.xx, 436.xx \\
\hline Myocardial infarction & ICD-9-CM diagnosis & $410 . x x$ \\
\hline Unstable angina pectoris & ICD-9-CM diagnosis & $411.1 x$ \\
\hline Heart failure & ICD-9-CM diagnosis & $428 . x x$ \\
\hline \multirow{4}{*}{$\begin{array}{l}\text { Percutaneous coronary } \\
\text { intervention }\end{array}$} & ICD-9-CM procedure & $00.66,36.06,36.07,17.55$ \\
\hline & CPT (all years) & $92980,92981,92982,92984,92995,92996$ \\
\hline & CPT (year 2013 onwards) & $\begin{array}{l}\text { 92920, 92921, 92924, 92925, 92928, 92929, 92933, 92934, 92937, 92938, 92941, } \\
\text { 92943, } 92944\end{array}$ \\
\hline & HCPCS & G0290, G0291 \\
\hline \multirow[t]{3}{*}{ Coronary artery bypass graft } & ICD-9-CM procedure & $36.10,36.11,36.12,36.13,36.14,36.15,36.16,36.17,36.19$ \\
\hline & $\mathrm{CPT}$ & $\begin{array}{l}33510,33511,33512,33513,33514,33516,33517,33518,33519,33521,33522, \\
33523,33530,33533,33534,33535,33536\end{array}$ \\
\hline & HCPCS & S2205, S2206, S2207, S2208, S2209 \\
\hline \multirow[t]{2}{*}{ Peripheral vascular disease } & ICD-9-CM diagnosis & 441.xx, 443.9x, 785.4x, v43.4x \\
\hline & ICD-9-CM procedure & 38.48 \\
\hline \multicolumn{3}{|l|}{ Microvascular disease } \\
\hline Diabetic nephropathy & ICD-9-CM diagnosis & 250.4 \\
\hline Diabetic retinopathy & ICD-9-CM diagnosis & $350.5,362.0 x$ \\
\hline Diabetic peripheral neuropathy & ICD-9-CM diagnosis & $250.6,357.2 x$ \\
\hline Hypertension & ICD-9-CM diagnosis & 401.xx, 402.xx, 403.xx, 404.xx, 405.xx \\
\hline Dyslipidemia & ICD-9-CM diagnosis & $272 . x x$ \\
\hline Depression & ICD-9-CM diagnosis & $296.2 x, 296.3 x, 311 . x x$ \\
\hline Hypoglycemia & ICD-9-CM diagnosis & $251.0 x, 251.1 x, 251.2 x, 250.8 x$ \\
\hline Antidiabetes Medication Classes & & Generic Names \\
\hline Alpha-glucosidase inhibitors & \multicolumn{2}{|l|}{ Acarbose, Miglitol } \\
\hline Biguanides & \multicolumn{2}{|l|}{ Metformin Hydrochloride } \\
\hline $\begin{array}{l}\text { Dipeptidyl peptidase-4 (DPP-4) } \\
\text { inhibitors }\end{array}$ & \multicolumn{2}{|c|}{ Alogliptin Benzoate, Linagliptin, Saxagliptin Hydrochloride, Sitagliptin Phosphate } \\
\hline Dopamine receptor agonists & \multicolumn{2}{|l|}{ Bromocriptine Mesylate } \\
\hline Meglitinide analogs & \multicolumn{2}{|l|}{ Nateglinid, Repaglinide } \\
\hline Sulfonylurea derivatives & \multicolumn{2}{|c|}{ Acetohexamide, Chlorpropamide, Glimepiride, Glipizide, Glyburide, Tolazamide, Tolbutamide, Tolbutamide Sodium } \\
\hline Thiazolidinediones & \multicolumn{2}{|c|}{ Pioglitazone Hydrochloride, Rosiglitazone Maleate, Troglitazone } \\
\hline
\end{tabular}



Human/Insulin Release Unit/Chamber/Inhaler, Insulin Detemir, Insulin Lispro Protamine \& Insulin Lispro, Insulin Human Regular, Insulin Glargine Recombinant, Insulin Aspart Recombinant, Insulin Human Isophane (Nph), Insulin Human Isophane (Nph)/Insulin Human Regular, Insulin Lispro Recombinant, Insulin Lispro/Insulin Lispro Protamine, Insulin Aspart/Insulin Aspart Protamine, Insulin Isophane Nph Bf-Pk, Insulin Isophane Beef, Insulin Isophane Beef Pure, Insulin Isophane Pork Pure, Insulin Protamine Zinc Beef, Insulin Protamine Zn Beef (P), Insulin Protamine Zn Bf-Pk, Insulin Protamine Zn Pork (P), Insulin Reg Hum S-S Buff, Insulin Regular Beef-Pork, Insulin Regular Human Buffered, Insulin Zinc Beef, Insulin Zinc Ext Beef (P), Insulin Zinc Extend Human Rec, Insulin Zinc Extended Beef, Insulin Zinc Extended Bf-Pk, Insulin Zinc Human Rec, Insulin Zinc Human Semi-Syn, Insulin Zinc Prompt Beef, Insulin Zinc Prompt Bf-Pk, Insulin Zinc Prompt Pork Pure, Insulin Zinc Beef Purified, Insulin Zinc Beef Purified/Insulin Zinc Pork Purified, Insulin Zinc Beef-Pork, Insulin Zinc Pork Purified, Insulin Beef, Insulin Pork, Insulin Pork Purified, Insulin Pork Purified/Insulin Isophane Pork Pure, Insulin Pork Reg. Concentrate

Glucagon-like peptide 1 receptor agonists (GLP-1 RA) Sodium glucose co-transporter 2 (SGLT2) inhibitors

Antidiabetes Combination Medication Classes

Metformin/dipeptidyl peptidase-4

Thiazolidinediones/dipeptidyl peptidase-4

Dipeptidyl peptidase-4/statins

Metformin/Meglitinide

Metformin/Sulfonylurea

Thiazolidinediones /sulfonylurea Metformin/ thiazolidinediones

Antihypertensive

Medication Classes

Renin-angiotensin-aldosterone system (RAAS) blocking agents

Beta blockers

Calcium channel blockers

Diruetics

Vasodilators

Peripheral vasodilators

Central alpha-2 receptor agonists

Ganglionic blocking,

non-depolarizing

Peripheral alpha-1 receptor blockers

Postganglionic blockers,

antihypertensive

Pulmonary antihypertensive agents

Reserpine and derivatives

\section{Generic Names}

Metformin Hydrochloride/Saxagliptin Hydrochloride, Metformin Hydrochloride/Sitagliptin Phosphate, Linagliptin/ Metformin Hydrochloride, Alogliptin Benzoate/Metformin Hydrochloride

Alogliptin Benzoate/Pioglitazone Hydrochloride

Simvastatin/Sitagliptin Phosphate

Metformin Hydrochloride/Repaglinide

Glipizide/Metformin Hydrochloride, Glyburide/Metformin Hydrochloride

Glimepiride/Pioglitazone Hydrochloride, Glimepiride/Rosiglitazone Maleate

Metformin Hydrochloride/Pioglitazone Hydrochloride, Metformin Hydrochloride/Rosiglitazone Maleate

\section{Generic Names}

Aliskiren Hemifumarate, Azilsartan Medoxomil, Benazepril Hcl, Candesartan Cilexetil, Captopril, Enalapril Maleate, Enalaprilat Dihydrate, Eprosartan Mesylate, Fosinopril Sodium, Irbesartan, Lisinopril, Lisinopril/Dietary Supplement Comb.10, Losartan Potassium, Moexipril Hcl, Olmesartan Medoxomil, Perindopril Erbumine, Quinapril Hcl, Ramipril, Telmisartan, Trandolapril, Valsartan

Acebutolol Hcl, Atenolol, Betaxolol Hcl, Bisoprolol Fumarate, Carteolol Hcl, Carvedilol, Carvedilol Phosphate, Labetalol Hcl, Metoprolol Succinate, Metoprolol Tartrate, Metoprolol Tartrate/Dietary Supplement Comb.10, Nadolol, Nebivolol Hcl, Penbutolol Sulfate, Pindolol, Propranolol Hcl, Timolol Maleate

Amlodipine Besylate, Bepridil Hcl, Clevidipine Butyrate, Diltiazem Hcl, Diltiazem Hcl In 0.9 \% Sodium Chloride, Diltiazem Hcl/Dextrose 5 \% In Water, Diltiazem Malate, Felodipine, Isradipine, Mibefradil Di-Hcl, Nicardipine Hcl, Nicardipine In Dextrose 5 \%-Water, Nicardipine In Dextrose Iso-Osmotic, Nicardipine In Sodium Chloride IsoOsmotic, Nifedipine, Nimodipine, Nisoldipine, Verapamil Hcl

Acetazolamide, Bumetanide, Polythiazide

Diazoxide, Fenoldopam Mesylate, Hydralazine Hcl, Minoxidil, Nitroprusside Sodium, Tolazoline Hcl

Ethaverine Hcl, Isoxsuprine Hcl, Papaverine Hcl

Clonidine, Clonidine Hcl, Guanabenz Acetate, Guanfacine Hcl, Methyldopa, Methyldopate Hcl

Mecamylamine $\mathrm{Hcl}$

Doxazosin Mesylate, Phenoxybenzamine Hcl, Phentolamine Mesylate, Prazosin Hcl, Terazosin Hcl

Guanadrel Sulfate, Guanethidine Sulfate

Ambrisentan, Bosentan, Epoprostenol Sodium (Arginine), Epoprostenol Sodium (Glycine), Iloprost, Nitric Oxide, Sildenafil Citrate, Tadalafil, Treprostinil, Treprostinil Sodium, Treprostinil/Nebulizer Accessories, Treprostinil/ Nebulizer/Nebulizer Accessories

Reserpine 


\section{APPENDIX A Study Codes and Medications ${ }^{a}$ (continued)}

Antihypertensive Combination Medication Classes

Antihypertensive combinations

\section{Generic Names}

Aliskiren Hemifumarate/Amlodipine Besylate, Aliskiren Hemifumarate/Amlodipine/Hydrochlorothiazide, Aliskiren Hemifumarate/Hydrochlorothiazide, Aliskiren/Valsartan, Amiloride Hcl/Hydrochlorothiazide, Amlodipine Besylate/Atorvastatin Calcium, Amlodipine Besylate/Benazepril Hcl, Amlodipine Besylate/Olmesartan Medoxomil, Amlodipine Besylate/Valsartan, Amlodipine Besylate/Valsartan/Hydrochlorothiazide, Atenolol/ Chlorthalidone, Azilsartan Medoxomil/Chlorthalidone, Benazepril Hcl/Hydrochlorothiazide, Bisoprolol umarate/ Hydrochlorothiazide, Candesartan Cilexetil/Hydrochlorothiazide, Captopril/Hydrochlorothiazide, Clonidine Hcl/Chlorthalidone, Deserpidine/Hydrochlorothiazide, Deserpidine/Methyclothiazide, Enalapril Maleate/ Diltiazem Malate, Enalapril Maleate/Felodipine, Enalapril Maleate/Hydrochlorothiazide, Eprosartan Mesylate/ Hydrochlorothiazide, Fosinopril Sodium/Hydrochlorothiazide, Guanethidine Sulfate/Hydrochlorothiazide, Hydralazine Hcl/Hydrochlorothiazide, Hydralazine Hcl/Reserpine/Hydrochlorothiazide, Irbesartan/ Hydrochlorothiazide, Isosorbide Dinitrate/Hydralazine Hcl, Lisinopril/Hydrochlorothiazide, Losartan Potassium/ Hydrochlorothiazide, Methyldopa/Chlorothiazide, Methyldopa/Hydrochlorothiazide, Metoprolol Succinate/ Hydrochlorothiazide, Metoprolol Tartrate/Hydrochlorothiazide, Moexipril Hcl/Hydrochlorothiazide, Nadolol/ Bendroflumethiazide, Olmesartan Medoxomil/Amlodipine Besylate/Hydrochlorothiazide, Olmesartan Medoxomil/ Hydrochlorothiazide, Potassium Salicylate/Salicylamide/Caffeine, Prazosin Hcl/Polythiazide, Propranolol Hcl/ Hydrochlorothiazide, Quinapril Hcl/Hydrochlorothiazide, Rauwolfia Serpentina/Bendroflumethiazide, Reserpine/ Chlorothiazide, Reserpine/Hydrochlorothiazide, Reserpine/Hydroflumethiazide, Reserpine/Methyclothiazide, Reserpine/Polythiazide, Spironolactone/Hydrochlorothiazide, Telmisartan/Amlodipine Besylate, Telmisartan/ Hydrochlorothiazide, Timolol Maleate/Hydrochlorothiazide, Trandolapril/Verapamil Hcl, Triamterene/ Hydrochlorothiazide, Valsartan/Hydrochlorothiazide

Antihyperlipid Medication Classes Antihyperlipids

\section{Generic Names}

Amlodipine Besylate/Atorvastatin Calcium, Aspirin (Calcium Carb \& Magnesium Buffers)/Pravastatin, Atorvastatin Calcium, Cerivastatin Sodium, Cholestyramine, Cholestyramine (With Sugar), Cholestyramine/Aspartame, Clofibrate, Colesevelam Hcl, Colesevelam Hydrochloride, Colestipol Hcl, Ezetimibe, Ezetimibe/Simvastatin, Fenofibrate, Fenofibrate Nanocrystallized, Fenofibrate Micronized, Fenofibrate Micronized, Fenofibric Acid, Fenofibric Acid (Choline), Fluvastatin Sodium, Gemfibrozil, Lecithin/Sitosterols/Niacin/Betaine/Chitosan, Lovastatin, Melatonin/Tryptophan/Valerian/Chamomile/Niacin/Inositol/B6, Niacin, Niacin/Lovastatin, Niacin/Simvastatin, Pitavastatin Calcium, Policosanol/Inositol Niacinate/Garlic, Pravastatin Sodium, Rosuvastatin Calcium, Simvastatin, Sitagliptin Phosphate/Simvastatin

aCodes measured over time period January 1, 2007-June 30, 2012, unless otherwise noted.

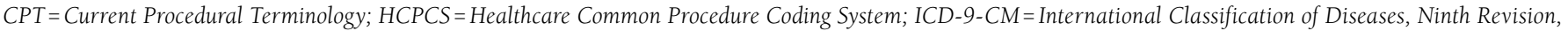
Clinical Modification; MS-DRG=Medicare Severity Diagnosis-Related Group. 
APPENDIX B Unadjusted NCQA/HEDIS Comprehensive Diabetes Care and Clinical Outcomes During Outcomes Follow-up Period

\begin{tabular}{|c|c|c|c|c|c|c|c|c|}
\hline & \multicolumn{4}{|c|}{ Primary Analysis Sample } & \multicolumn{4}{|c|}{ Subgroup Samplea } \\
\hline & \multicolumn{2}{|c|}{$\begin{array}{l}\text { Weight Gain Group } \\
\qquad \mathbf{n}=325\end{array}$} & \multicolumn{2}{|c|}{$\begin{array}{c}\text { Nonweight Gain Group }{ }^{\mathrm{b}} \\
\mathrm{n}=1,195\end{array}$} & \multicolumn{2}{|c|}{$\begin{array}{l}\text { Weight Gain Group } \\
\qquad \mathbf{n}=134\end{array}$} & \multicolumn{2}{|c|}{$\begin{array}{l}\text { Nonweight Gain Group } \\
n=646\end{array}$} \\
\hline \multicolumn{9}{|l|}{ Alc (as \%) } \\
\hline Follow-up measurement, mean [SD] & 7.4 & {$[1.4]$} & 7.1 & {$[1.2]$} & 7.4 & {$[1.3]$} & 7.1 & {$[1.2]$} \\
\hline Poor control (>9.0), \% (n) & 10.5 & $(34)$ & 6.8 & $(81)$ & 11.9 & $(16)$ & 6.7 & (43) \\
\hline Control $(<8.0), \%(n)$ & 75.4 & $(245)$ & 83.0 & $(992)$ & 73.9 & (99) & 84.4 & $(545)$ \\
\hline Control $(<7.0), \%(n)$ & 44.3 & $(144)$ & 54.9 & $(656)$ & 44.0 & $(59)$ & 54.8 & $(354)$ \\
\hline Control $(<6.5), \%(\mathrm{n})$ & 24.3 & $(79)$ & 32.4 & $(387)$ & 24.6 & $(33)$ & 31.3 & $(202)$ \\
\hline \multicolumn{9}{|l|}{ Blood pressure $(\mathrm{mm} \mathrm{Hg})$} \\
\hline Follow-up systolic, mean [SD] & 112.3 & [16.2] & 112.3 & {$[17.1]$} & 109.7 & {$[15.5]$} & 113.4 & {$[17.4]$} \\
\hline Follow-up diastolic, mean [SD] & 87.7 & {$[15.6]$} & 88.3 & {$[15.7]$} & 85.5 & [14.9] & 89.6 & {$[16.0]$} \\
\hline Control (<130/80 mm Hg), \% (n) & 30.8 & $(100)$ & 29.8 & $(356)$ & 36.6 & (49) & 26.9 & (174) \\
\hline Control (<140/90 mm Hg), \% (n) & 56.6 & $(184)$ & 54.2 & $(648)$ & 65.7 & $(88)$ & 51.9 & $(335)$ \\
\hline LDL-C (mg/dL)c & \multicolumn{2}{|c|}{$\mathrm{n}=150$} & \multicolumn{2}{|c|}{$n=606$} & \multicolumn{2}{|c|}{$n=61$} & \multicolumn{2}{|c|}{$\mathrm{n}=342$} \\
\hline Follow-up measurement, mean [SD] & 92.8 & {$[29.6]$} & 92.5 & {$[33.0]$} & 91.5 & {$[27.0]$} & 92.8 & {$[33.4]$} \\
\hline Control (<100 mg/dL), \% (n) & 64.7 & (97) & 64.2 & $(389)$ & 67.2 & $(41)$ & 62.0 & $(212)$ \\
\hline \multicolumn{9}{|c|}{$\begin{array}{l}\text { a Sample restricted to patients with } B M I \geq 30 \text { and no evidence of previous cardiovascular disease. } \\
\text { bWeight gain=increase in weight by }>3 \% ; \text { nonweight gain= weight gain } \leq 3 \% \text { and weight loss. } \\
\text { cAnalyses conducted on a subset of patients for whom } L D L-C \text { data were available. } \\
\text { Alc=hemoglobin Alc; BMI=body mass index; } L D L-C=\text { low-density lipoprotein cholesterol; NCQA/HEDIS=National Committee for Quality Assurance/Healthcare } \\
\text { Effectiveness Data and Information Set; SD = standard deviation. }\end{array}$} \\
\hline
\end{tabular}


APPENDIX C Unadjusted All-Cause Health Care Utilization and Costs During Outcomes Follow-up Period

\begin{tabular}{|c|c|c|c|c|c|c|c|c|}
\hline & \multicolumn{4}{|c|}{ Primary Analysis Sample } & \multicolumn{4}{|c|}{ Subgroup Samplea } \\
\hline & \multicolumn{2}{|c|}{$\begin{array}{l}\text { Weight Gain Group } \\
\qquad \mathrm{n}=325\end{array}$} & \multicolumn{2}{|c|}{$\begin{array}{l}\text { Nonweight Gain Group } \\
\qquad \mathrm{n}=1,195\end{array}$} & \multicolumn{2}{|c|}{$\begin{array}{l}\text { Weight Gain Group } \\
\qquad \mathbf{n}=134\end{array}$} & \multicolumn{2}{|c|}{$\begin{array}{l}\begin{array}{l}\text { Nonweight Gain Group } \\
\mathrm{b}=646\end{array} \\
\qquad\end{array}$} \\
\hline \multicolumn{9}{|l|}{ Inpatient admissions } \\
\hline Patients with an inpatient admission, \% (n) & 11.7 & $(38)$ & 10.4 & $(124)$ & 11.2 & $(15)$ & 8.4 & $(54)$ \\
\hline Number of inpatient admissions, mean [SD] & 0.2 & {$[0.5]$} & 0.1 & {$[0.5]$} & 0.2 & {$[0.6]$} & 0.1 & {$[0.4]$} \\
\hline Inpatient expenditures, mean [SD] & $\$ 3,694$ & {$[\$ 13,938]$} & $\$ 3,149$ & {$[\$ 14,371]$} & $\$ 4,674$ & {$[\$ 17,585]$} & $\$ 2,131$ & {$[\$ 9,791]$} \\
\hline \multicolumn{9}{|l|}{ Emergency room visits } \\
\hline Patients with an ER visit, \% (n) & 23.7 & $(77)$ & 20.8 & $(249)$ & 26.1 & $(35)$ & 21.4 & $(138)$ \\
\hline Number of ER visits, mean [SD] & 0.4 & [1.3] & 0.3 & {$[0.8]$} & 0.5 & {$[1.8]$} & 0.3 & {$[0.8]$} \\
\hline ER expenditures, mean [SD] & $\$ 312$ & {$[\$ 1,195]$} & $\$ 243$ & [\$836] & $\$ 395$ & {$[\$ 1,621]$} & $\$ 255$ & [\$773] \\
\hline \multicolumn{9}{|l|}{ Outpatient office visits and services } \\
\hline Patients with outpatient services, \% (n) & 100.0 & $(325)$ & 100.0 & $(1,195)$ & 100.0 & $(134)$ & 100.0 & $(646)$ \\
\hline Number of outpatient services, mean [SD] & 46.8 & [36.1] & 51.9 & [43.3] & 46.8 & [39.9] & 48.1 & {$[35.7]$} \\
\hline Outpatient services expenditures, mean [SD] & $\$ 5,579$ & {$[\$ 7,446]$} & $\$ 6,428$ & {$[\$ 13,187]$} & $\$ 4,935$ & {$[\$ 5,970]$} & $\$ 5,388$ & {$[\$ 11,928]$} \\
\hline \multicolumn{9}{|l|}{ Pharmacy } \\
\hline Number of prescription claims, mean [SD] & 42.4 & {$[28.5]$} & 41.9 & [27.2] & 44.0 & {$[28.6]$} & 41.3 & 27.9 \\
\hline Prescription drug expenditures, mean [SD] & $\$ 3,537$ & {$[\$ 3,723]$} & $\$ 4,026$ & {$[\$ 4,716]$} & $\$ 4,137$ & {$[\$ 4,750]$} & $\$ 3,922$ & {$[\$ 4,993]$} \\
\hline \multicolumn{9}{|l|}{ Total cost of health care services } \\
\hline Mean [SD] & $\$ 13,122$ & {$[\$ 18,630]$} & $\$ 13,845$ & {$[\$ 24,645]$} & $\$ 14,140$ & {$[\$ 21,911]$} & $\$ 11,696$ & {$[\$ 18,987]$} \\
\hline Median & \multicolumn{2}{|c|}{$\$ 7,126$} & \multicolumn{2}{|c|}{$\$ 7,110$} & \multicolumn{2}{|c|}{$\$ 6,743$} & \multicolumn{2}{|c|}{$\$ 6,626$} \\
\hline
\end{tabular}




\section{APPENDIX D Unadjusted Diabetes-Specific Health Care Utilization and Costs During Outcomes} Follow-up Period

\begin{tabular}{|c|c|c|c|c|c|c|c|c|}
\hline & & Primary A & lysis Sampl & & & Subgro & Sample ${ }^{a}$ & \\
\hline & $\begin{array}{r}\text { Weight } \mathrm{C} \\
\mathbf{n}=\end{array}$ & $\begin{array}{l}\text { ain Group } \\
325\end{array}$ & $\begin{array}{r}\text { Nonweight } \\
\mathbf{n}=\end{array}$ & $\begin{array}{l}\text { Gain Group } \\
1,195\end{array}$ & $\begin{array}{r}\text { Weight } \\
\mathrm{n}=\end{array}$ & $\begin{array}{l}\text { ain Group } \\
134\end{array}$ & $\begin{array}{r}\text { Nonweight } \\
\mathrm{n}=\end{array}$ & $\begin{array}{l}\text { Sain } \text { Group }^{\mathrm{b}} \\
546\end{array}$ \\
\hline Inpatient admissions & & & & & & & & \\
\hline Patients with an inpatient admission, \% (n) & 8.3 & $(27)$ & 7.4 & $(89)$ & 9.0 & $(12)$ & 6.0 & $(39)$ \\
\hline Number of inpatient admissions, mean [SD] & 0.1 & {$[0.4]$} & 0.1 & {$[0.4]$} & 0.1 & {$[0.5]$} & 0.1 & {$[0.3]$} \\
\hline Inpatient expenditures, mean [SD] & $\$ 2,676$ & {$[\$ 12,066]$} & $\$ 2,046$ & {$[\$ 10,204]$} & $\$ 3,852$ & {$[\$ 16,388]$} & $\$ 1,405$ & {$[\$ 7,510]$} \\
\hline Emergency room visits & & & & & & & & \\
\hline Patients with an ER visit, \% (n) & 8.0 & $(26)$ & 7.9 & (95) & 6.0 & (8) & 8.7 & $(56)$ \\
\hline Number of ER visits, mean [SD] & 0.1 & {$[0.5]$} & 0.1 & {$[0.4]$} & 0.1 & {$[0.6]$} & 0.1 & {$[0.4]$} \\
\hline ER expenditures, mean [SD] & $\$ 77$ & [\$439] & $\$ 75$ & {$[\$ 414]$} & $\$ 47$ & {$[\$ 316]$} & $\$ 76$ & {$[\$ 402]$} \\
\hline Outpatient office visits and services & & & & & & & & \\
\hline Patients with outpatient services, \% (n) & 98.8 & $(321)$ & 98.6 & $(1,178)$ & 98.5 & $(132)$ & 98.6 & $(637)$ \\
\hline Number of outpatient services, mean [SD] & 16.9 & {$[13.6]$} & 16.7 & {$[14.0]$} & 16.6 & {$[15.1]$} & 16.5 & {$[12.0]$} \\
\hline Outpatient services expenditures, mean [SD] & $\$ 1,406$ & {$[\$ 2,643]$} & $\$ 1,597$ & {$[\$ 6,934]$} & $\$ 1,176$ & {$[\$ 1,855]$} & $\$ 1,585$ & {$[\$ 8,754]$} \\
\hline Pharmacy & & & & & & & & \\
\hline Number of prescription claims, mean [SD] & 11.0 & {$[7.7]$} & 10.0 & {$[6.9]$} & 10.7 & {$[7.2]$} & 10.1 & {$[6.9]$} \\
\hline Prescription drug expenditures, mean [SD] & $\$ 1,134$ & {$[\$ 1,408]$} & $\$ 1,272$ & {$[\$ 1,470]$} & $\$ 1,217$ & {$[\$ 1,611]$} & $\$ 1,296$ & {$[\$ 1,560]$} \\
\hline Total cost of health care services & & & & & & & & \\
\hline Mean [SD] & $\$ 5,293$ & {$[\$ 12,536]$} & $\$ 4,990$ & {$[\$ 13,694]$} & $\$ 6,292$ & {$[\$ 16,702]$} & $\$ 4,362$ & {$[\$ 12,477]$} \\
\hline Median & & 949 & & 953 & & 897 & & \\
\hline
\end{tabular}

